УДК 316

$10.17213 / 2075-2067-2021-3-69-76$

\title{
ПРОБЛЕМЫ ФОРМИРОВАНИЯ СИСТЕМЫ МОНИТОРИНГА ИНТЕГРАЦИИ ИММИГРАНТОВ В РЕГИОНАЛЬНУЮ СРЕДУ
}

\author{
(C) 2021 г. В. А. Сапрыка, С. А. Олейник
}

\section{Белгородский государственный национальный исследовательский университет, 2. Белгород, Россия}

Целью исследования является обоснование концеепиий и практики управления процессами интеграчии иммигрантов в принимающую среду приграничного региона.

Методологическую базу исследования представляют как классические сочиологические теории (П. Бурдье, Э. Гидденса, Дж. Холлифилда, К. Бреттелла), так и работы в сфере социологии миграции, в частности Т.Н. Юдиной и Ж. М. Зайончковской. Также в исследовании использованы методы и принцииы С. Г. Максимовой и Г.И. Осадчей, которые посвящеены анализу миграционных процессов на постсоветском пространстве. К методологии исследования относится и концепция технологизаџии социиальных процессов, которая позволяет сформировать эффективный мониторинг интеграции иммигантов в принимающее сообщество приграничного региона (В. П. Бабиниев, Н. С. Данакин).

Результаты исследования. Миграчионные прочессы в современной сочиологии все чаще попадают в фокус внимания ученых. Однако зачастую проводимые исследования раскрывают процессы адаптаџии и интеграции мигрантов без учета необходимости измерения траекторий изменения статуса и иенностных установок иммигрантов в приграничном регионе.

Настоящее исследование представляет собой попытку формирования системь регионального мониторинга интеграџии иммигрантов в принимающую среду российского приграничья.

Перспективу исследования составляет будущуая социологическая интерпретация процессов интеграции иммигрантов в принимающую среду приграничных регионов России.

Ключевые слова: иммигрант; приграничный регион; мониторинг.

\section{PROBLEMS OF THE FORMATION OF A MONITORING SYSTEM FOR THE INTEGRATION OF IMMIGRANTS INTO THE REGIONAL ENVIRONMENT}

\author{
(C) $2021 \quad$ V. A. Sapryka, S. A. Oleinik \\ Belgorod State University, Belgorod, Russia
}

The aim of the study is to substantiate the concepts and practices of managing the integration of immigrants into the host environment of the border region.

The methodological basis of the research is represented by both classical sociological theories (P. Bourdieu, E. Giddens, J. Hallifield, K. Brettell) and works in the field of sociology of migration, in particular, T.N. Yudina and Zh. M. Zayonchkovskaya. Also, the study used the methods and principles of S. G. Maximova and G. I. Osadchy, which are devoted to the analysis of migration processes in the post-Soviet space. The research methodology also includes the concept 
of technologization of social processes, which makes it possible to form an effective monitoring of the integration of immigrants into the host community of the border region (V.P. Babintsev, N.S. Danakin).

Research results. Migration processes in modern sociology are increasingly becoming the focus of attention of scientists. However, often conducted studies reveal the processes of adaptation and integration of migrants without taking into account the need to measure the trajectories of changes in the status and value attitudes of immigrants in the border region.

This study is an attempt to form a system of regional monitoring of the integration of immigrants into the receiving environment of the Russian borderlands.

The prospect of the research is the future sociological interpretation of the processes of integration of immigrants into the host environment of the border regions of Russia.

Key words: immigrant; border region; monitoring.

Введение. Ведущие методологические подходы изучения интеграции иммигрантов. Особый интерес для изучения различных аспектов интеграции иммигрантов приобретают страны с «новыми» границами, появившиеся после распада СССР, Югославии, Чехословакии и т.д. Зачастую в них наблюдаются ярко выраженные явления иммиграции, которые сконцентрированы именно в приграничных территориях. Это обусловлено тем, что граница с течением времени усиливает здесь свою барьерную функцию и разрушает привычный социокультурный ландшафт, а иногда приводит к эскалации этнических конфликтов. При таком положении вещей бывшие соседи превращаются в граждан чужого, иногда даже враждебного государства. Ярким примером является обострение политической напряженности в российско-украинском приграничье.

Однако построение адекватной современным реалиям системы управления интеграционными процессами в сфере миграции на региональном уровне невозможно без теоретико-методологического осмысления данного явления. Рассмотрим основные методологические основы для изучения проблем интеграции иммигрантов.

В своих работах М. Гордон предложил одномерную модель ассимиляции, по которой члены группы, представляющей меньшинство, теряют свою первоначальную культурную идентичность, поскольку приобретают новую идентичность в новой культуре. Работы представляют большой инте- рес, так как позволяют выделить критерии для создания системы регионального мониторинга интеграции иммигрантов в принимающую среду. Ученый выделил 7 типов ассимиляции [1].

Заслуживают внимания труды Дж. Берри, где впервые было выделено четыре стратегии аккультурации личности: ассимиляция, сепарация, маргинализация и интеграция [2]. Для настоящего исследования особый интерес представляет именно понятие интеграции. Это продиктовано тем, что это сложное многоуровневое явление охватывает в том числе управленческие процессы.

Выделенные Д. Хелдом, Д. Голдблаттом и Э. Макгрю модели этносоциальной интеграции стали базисом для дальнейшего социологического осмысления процессов миграции в приграничном регионе [3].

Большое внимание интеграционным процессам в сфере миграции уделено и в работах отечественных социологов Г. И. Осадчей, Т.Н. Юдиной и Ж.М. Зайончковской, разрабатывающих методологию изучения миграционных процессов на пространстве ЕАЭС $[8,9]$. С.Г. Максимовой были предложены методы для анализа функционирования приграничных региональных социумов [11].

Технология оценки эффективности регионального управления на основе показателей качества жизни населения, внедренная В.П. Бабинцевым, позволила сформировать индикаторы и критерии мониторинга интеграции иммигрантов в принимающую среду приграничного региона [12]. 
Модель системы мониторинга интеграции иммигрантов в принимающее сообщество приграничного региона. Миграционные процессы, проходящие в приграничных регионах, зачастую носят маятниковый характер, который сложно оценить в социальном времени и пространстве. Приграничное взаимодействие характеризуется активной маятниковой миграцией, которая зачастую растягивается во времени и пространстве на продолжительный период. Так, житель приграничной территории может стать мигрантом, иммигрантом, репатриантом и ощутить на себе всю тяжесть барьерной функции границы. Данные процессы требуют тщательной социологической диагностики, оценки влияния иммигрантов на принимающее сообщество, а также специфических управленческих механизмов для будущей интеграции.

Управленческая составляющая механизма проведения социологического мониторинга региональной миграционной среды включает формы и методы управления мониторингом, отдельными процессами, а также управленческую структуру и систему прав и обязанностей должностных лиц по поводу их участия в реализации процессов мониторинга и использования его результатов.

Анализ стрессовой составляющей миграции в условиях приграничных регионов позволяет сгруппировать факторы, влияющие на интеграцию, следующим образом:

1) культурно-коммуникативные: овладение культурными особенностями, языком общения, информацией о специфике функционирования и развития регионального сообщества и входящих в него групп; расширение устойчивых межкультурных и социальных контактов; культурные идентификации с сообществом;

2) морально-психологические, включающие мотивирование интеграции, установки на конструктивное взаимодействие с принимающим сообществом, активность и планирование будущего, позитивное восприятие себя как части нового социума;

3) экономические, т.е. предоставляющие иммигрантам доступ к получению благ, необходимых для нормальной жизнедеятельности;

4) социальные, т.е. предполагающие соблюдение общих правил, обязательных и же- лательных в принимающем обществе, возможность участия в принятии решений и др.;

5) идентификационные - осознание иммигрантами тождественности с региональным сообществом, культурной общностью, обретение региональной идентичности.

С учетом специфики отдельно взятого приграничного региона при проведении мониторинга уровня интегрированности иммигрантов в принимающее сообщество представляется необходимым анализ по следующим критериям, представленным в рисунке 1.

При проведении мониторинга уровня интеграции иммигрантов в принимающую среду приграничного региона также необходимо принимать во внимание, насколько однородно региональное сообщество, позитивно либо негативно восприятие этнокультурной идентичности с обеих сторон, универсальность региональной идентичности, принятие и понимание традиций и обычаев разных культур (этнокультурная толерантность), а также включенность в этнокультурное пространство неродной страны.

Как было отмечено выше, особую значимость изучение проблематики интеграции иммигрантов приобретает в российско-украинском пограничье. Это продиктовано рядом причин:

- изменением с течением времени соотношения контактной и барьерной функций государственной границы;

- несоответствием реализуемой государственной миграционной политики уровню социокультурной общности населения приграничных регионов России и Украины;

- асинхронностью социальных, культурных и экономических трансформаций по обе стороны границы.

Существенный рост числа иммигрантов из восточных регионов Украины, происходящий в последние годы, требует срочной актуализации инструментария интеграции переселенцев в российское общество. В этой связи видится целесообразным использование потенциала социокультурной близости населения российско-украинского приграничья.

Как отмечается в работах отечественных авторов, существует два основных фактора, определяющих социокультурную общность 
населения приграничных регионов России и Украины: во-первых, низкая до последнего времени степень барьерности границы, предопределившая высокую активность коммуникации между населением обеих стран; во-вторых, культурно-историческая общность приграничных территорий России и Украины, например, Белгородская и Харьковская области практически целиком входили в состав единого исторического региона - Слободской Украины (Слобожанщины), обладающей собственными культурными традициями и идентичностью.

Вместе с тем построение эффективной системы мониторинга миграционных про- цессов позволяет только диагностировать проблему и определить актуальный инструментарий поддержки интеграции иммигрантов в региональную среду. Внедрение эффективных методов в деятельность региональных властей представляется отдельной и весьма трудоемкой задачей. Ее решение затруднено ввиду базовых проблем отечественных систем управления, а именно:

- инертность организационных систем (старые нормы, проверенные шаблоны и пр.);

- противоречия новых механизмов традиционным методам деятельности;

- наличие авторитарных методов руководства;

\section{Высокая степень интегрированности}

1. Идентификация иммигрантов как равноправных субъектов региональных гражданских процессов.

2. Отсутствие конфликтов на межнациональной почве.

3. Эффективное сотрудничество иммигрантов и других представителей регионального сообщества процесса на формальном и неформальном уровнях.

4. Позитивное восприятие иммигрантов как части регионального сообщества.

5. Полная удовлетворенность иммигрантом своим статусом в региональном сообществе.

6. Понимание особенностей принимающей культуры, комфортность взаимодействия с неоднородной культурой.

7. Обретение региональной идентичности иммигрантами.

8. Устойчивое стремление к освоению социокультурного пространства региона.
Средняя степень интегрированности

1. Идентификация иммигрантов как субъектов региональных гражданских процессов, которые имеют ограниченные права.

2. Наличие скрытых конфликтов (напряженности) на межнациональной почве.

3. Сотрудничество иммигрантов и других представителей регионального сообщества носит вынужденный характер и не отличается высокой эффективностью.

4. Наличие отрицательных стереотипов об иммигрантах.

5. Частичная удовлетворенность иммигрантом своим статусом в региональном сообществе.

6. Состояние тревожности и неуверенности при взаимодействии с неродной культурой.

7. Этническая маргинальность иммигрантов.

8. Стремление к освоению социокультурного пространства региона ситуативное и выражено нечетко.

\section{Низкая степень} интегрированности

1. Открытая дискриминация иммигрантов как субъектов региональных гражданских процессов.

2. Открытая конфронтация на межнациональной почве.

3. Отсутствие постоянных контактов между иммигрантами и другими представителями регионального сообщества.

4. Негативное восприятие иммигрантов как части регионального сообщества.

5. Неудовлетворенность иммигрантами своим статусом в региональном сообществе.

6. Культурная сегрегация/ сепарация.

7. Негативное восприятие этнической идентичности иммигрантами.

8. Индифферентное отношение к освоению социокультурного пространства региона.

Рис. 1. Мониторинг уровня интегрированности иммигрантов 
- страх разрушения сложившихся устоев, традиций, привычек;

- стремление к мнимой «стабильности».

Безусловно, бесконтрольное переселение иммигрантов исключительно в приграничные регионы повлечет за собой существенные экономические и социальные проблемы в региональном развитии. Однако и перенаправление миграционных потоков в регионы, где социокультурная адаптация и интеграция для иммигрантов будут затруднены, не позволит добиться значимого эффекта от привлечения человеческих ресурсов в экономику региона.

В этой связи ключевым вопросом остается поиск баланса между возможностями социокультурной интеграции иммигрантов и экономическими эффектами миграции в приграничных регионах.

Решение социокультурной интеграции должно безусловно основываться на диалоге, когда коммуницирующие стороны взаимодействуют на основе толерантности, которая в свою очередь опирается на принципы полного «вхождения» в другую культуру - полное взаимопонимание и разделение, доверие и согласие.

Сегодня мир все более усложняется, усложняются и механизмы взаимодействия. В этой ситуации диалог становится все более востребованным, являясь необходимым для восстановления социокультурного порядка, а также для зарождения новых форм взаимодействия. Следствием вышеупомянутой социокультурной дезинтеграции является кризис социокультурной идентичности, суть которой состоит в росте несовместимости, амбивалентности, инкультурации и индивидуализации человека.

Эти качества репродуцируют социокультурную разобщенность, превозмочь которую может личность, направленная на развитие социокультурного взаимопроникновения, единства, предполагающего не просто интеграцию индивида, а усвоение всех норм, правил, ценностей того региона, в который интегрируется иммигрант. Нельзя не сказать о реально существующих коммуникативных барьерах пограничья, не считаться с которыми нельзя, поскольку сегодня именно они затрудняют процессы интеграции.

Любой вид коммуникации сам по себе не может формировать личность, осознаю- щую социокультурные проблемы принимающего общества. Они могут играть как созидательную, так и деструктивную роль в жизни общества.

Заключение. Российские приграничные регионы обладают существенным потенциалом для интеграции иммигрантов из сопредельных государств. В связи с этим многократно возрастает необходимость в активизации региональной миграционной политики, а также необходимость измерения миграционных процессов со смещением акцентов в сторону мониторинга интегративной составляющей иммиграции.

Система социальных механизмов интеграции иммигрантов в приграничных регионах должна носить адаптивный и системный характер, а также учитывать особенности специфики отдельного региона.

Одним из главных условий социокультурной интеграции как части общей интеграции иммигрантов должна быть ориентация на ценности и нормы организации коммуникативного процесса, направленная на исполнение созидательных возможностей коммуникативных взаимодействий, сохранение традиционного социокультурного пространства и межэтнического разнообразия приграничных регионов.

Предложенная в настоящей статье система мониторинга интегрированности иммигрантов в принимающую среду, предполагающая разделение на несколько уровней, может служить базой для разработки муниципальных и региональных программ интеграции.

\section{Литература}

1. Gordon M.M. Assimilation in American life: The Role of Race, Religion and National Origins. - New York, 1964. — 276 p.

2. Берри Дж., Пуртинга А. и др. Кросскультурная психология. Исследования и применение. - Харьков: Гуманитарный Центр, 2007.

3. Глобальные трансформации: Политика, экономика, культура: Пер. с англ. / Хелд Д., Голдблатт Д., Макгрю Э., Перратон Дж. - M., 2004. - T. XXIV. — 576 c.

4. Clemens M., Huang C., Graham J., Gough K. Migration Is What You Make It: Sev- 
en Policy Decision that Turned Challenges into Opportunities [Electronic resource] / Center for Global Development. - May 30, 2018. URL: https://www.cgdev.org/publication/migration-what-you-make-it-sevenpolicy-decisionsturned-challenges-opportunities.

5. Вахта В.M. Проблемы аккультурации в современной этнографической литературе США / В кн.: Современная американская этнография. - М., 1963.

6. Herskovitz M.J. Acculturation. The Study of Cultural Contact. — N. Y., 1938.

7. Linton R. Acculturation in Seven American Indian Tribes. - 1963.

8. Осадчая Г.И., Юдина Т.Н., Лескова И.В., Киреев Е.Ю. Межнациональные отношения мигрантов - граждан государств Евразийского экономического союза в московском мегаполисе // Социальная политика и социология. - 2020. - №2 (135). - С. 98-106.

9. Миграционная ситуация в странах СНГ / Под ред. Зайончковской Ж. - М.: Комплекс Прогресс, 1999.

10. Берендеев М.В. Методологические основания исследования идентичности регионального социума (на примере Калининградской области) // Социология образования. - 2007. - №7. - С. 51-57.

11. Гончарова Н.П., Максимова С.Г., Ноянзина О.Е., Омельченко Д.А., Авдеева Г.С. Методика формирования региональных выборок в социально-экономических исследованиях социальных рисков и безопасности населения приграничных территорий // Вестник АГАУ. - 2014. — №8 (118). C. 153-159.

12. Б Бабинцев В.П., Заливанский Б. В., Самохвалова Е.В., Шаповал Ж.А. Оценка эффективности регионального управления на основе показателей качества жизни населения [Электронный ресурс] // Регионология. - 2010. - №4. - Режим доступа: https:// cyberleninka.ru/article/n/otsenka-effektivnostiregionalnogo-upravleniya-na-osnovepokazateley-kachestva-zhizni-naseleniya (Дата обращения: 15.06.2021).

\section{References}

1. Gordon M.M. Assimilation in American life: The Role of Race, Religion and National Origins. — New York, 1964. - 276 p.
2. Berri Dzh., PurtingaA. et al. Krosskul'turnaja psihologija. Issledovanija i primenenie [Cross-cultural psychology. Research and application]. - Har'kov: Gumanitarnyj Centr, 2007.

3. Global'nye transformacii: Politika, jekonomika, kul'tura: Per. s angl. [Global transformations: Politics, Economics, culture: Trans. from English] / Held D., Goldblatt D., Makgrju Je., Perraton Dzh. - Moscow, 2004. Vol.XXIV. $-576 \mathrm{p}$.

4. Clemens M., Huang C., Graham J., Gough K. Migration Is What You Make It: Seven Policy Decision that Turned Challenges into Opportunities [Electronic resource] / Center for Global Development. — May 30, 2018. URL: https://www.cgdev.org/publication/migration-what-you-make-it-sevenpolicy-decisionsturned-challenges-opportunities.

5. Vahta V.M. Problemy akkul'turacii v sovremennoj jetnograficheskoj literature SShA [Problems of acculturation in the modern ethnographic literature of the United States] / V kn.: Sovremennaja amerikanskaja jetnografija [In the book: Modern American Ethnography]. — Moscow, 1963.

6. Herskovitz M.J. Acculturation. The Study of Cultural Contact. - N. Y., 1938.

7. Linton R. Acculturation in Seven American Indian Tribes. - 1963.

8. Osadchaja G.I., Judina T.N., Leskova I.V., Kireev E. Ju. Mezhnacional'nye otnoshenija migrantov - grazhdan gosudarstv Evrazijskogo jekonomicheskogo sojuza v moskovskom megapolise [Interethnic relations of migrants-citizens of the states of the Eurasian Economic Union in the Moscow megapolis] // Social'naja politika i sociologija [Social Policy and Sociology]. — 2020. — №2 (135). Pp. 98-106.

9. Migracionnaja situacija v stranah SNG [Migration situation in the CIS countries] / Pod red. Zajonchkovskoj Zh. [In Zayonchkovskaya Zh. (eds.)]. - Moscow: Kompleks Progress, 1999.

10. Berendeev M.V. Metodologicheskie osnovanija issledovanija identichnosti regional'nogo sociuma (na primere Kaliningradskoj oblasti) [Methodological foundations of the study of the identity of the regional society (on the example of the Kaliningrad region)] // Sociologija obrazovanija [Sociology of Education]. — 2007. — №7. Pp. 51-57. 
11. Goncharova N.P., Maksimova S. G., Nojanzina O.E., Omel'chenko D. A., Avdeeva G.S. Metodika formirovanija regional'nyh vyborok v social'no-jekonomicheskih issledovanijah social'nyh riskov i bezopasnosti naselenija prigranichnyh territorij [Methodology of forming regional samples in socio-economic studies of social risks and security of the population of border territories] // Vestnik AGAU. - 2014. №8 (118). - Pp. 153-159.

12. Babincev V.P., Zalivanskij B. V., Samohvalova E.V., Shapoval Zh. A. Ocenka jeffek- tivnosti regional'nogo upravlenija na osnove pokazatelej kachestva zhizni naselenija [Evaluation of the effectiveness of regional management on the basis of indicators of the quality of life of the population] [Jelektronnyj resurs] // Regionologija. - 2010. - №4. - URL: https:// cyberleninka.ru/article/n/otsenka-effektivnostiregionalnogo-upravleniya-na-osnove-pokazateley-kachestva-zhizni-naseleniya (Date accessed: 15.06.2021).

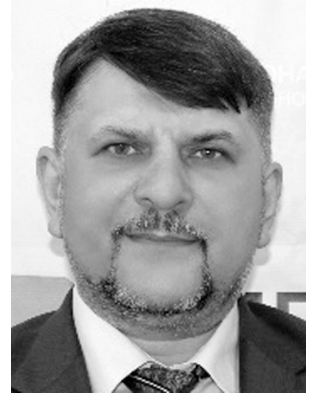

Сапрыка Виктор Александрович - заведующий кафедрой социальных технологий и государственной службы Белгородского государственного национального исследовательского университета.

Sapryka Viktor Alexandrovich - Head of the Department of Social Technologies and Public Service, Belgorod State National Research University.

308015 , г. Белгород, ул. Победы, 85

85 Pobedy st., 308015, Belgorod, Russia

E-mail: sapryka@bsu.edu.ru 


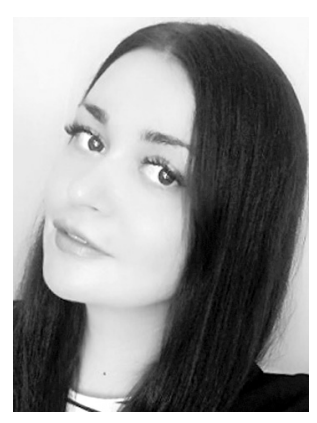

Олейник Светлана Анатольевна - соискатель кафедры социальных технологий и государственной службы Белгородского государственного национального исследовательского университета.

Oleinik Svetlana Anatolyevna - Postgraduate Student of the Department of Social Technologies and Public Service, Belgorod State National Research University.

308015, г. Белгород, ул. Победы, 85

85 Pobedy st., 308015, Belgorod, Russia

E-mail: oleiniksa@yandex.ru 